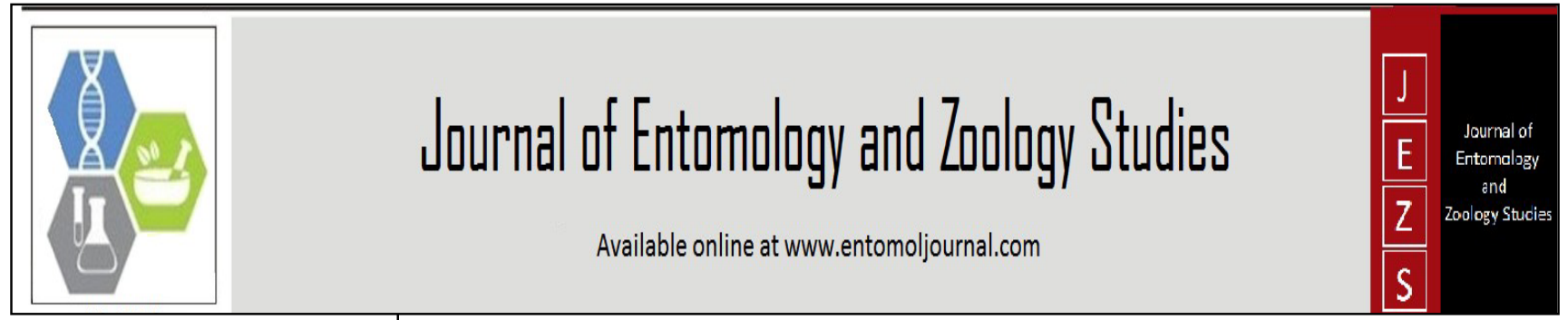

E-ISSN: 2320-7078

P-ISSN: 2349-6800

JEZS 2016; 4(1): 127-129

(C) 2015 JEZS

Received: 12-11-2015

Accepted: 14-12-2015

Mark Ian Cooper

Department of Biological Sciences, University of Cape Town, Private

Bag, Rondebosch 7701, Republic of South Africa.
Correspondence

Mark Ian Cooper

Department of Biological Sciences,

University of Cape Town, Private

Bag, Rondebosch 7701, Republic of

South Africa.

\section{Sperm storage in Centrobolus spp. and observational evidence for egg simulation}

\section{Mark Ian Cooper}

Abstract

Sperm storage organs and their controlling mechanisms are described for Centrobolus spp. The upper reproductive tract has separate insemination duct, spermatheca and oviduct. Muscles controlling sperm movement towards the spermatheca were identified as muscles of the bursa and gutter apodematique. Sensory apparatus connected to the spermathecae were identified. The presence of a fully developed egg in the bursa of $C$. inscriptus immediately after mating provides evidence for the egg simulation hypothesis in Spirobolida.

Keywords: egg simulation, bursa, copulatrix, millipede

\section{Introduction}

In Centrobolus spp., female physiology imposes both temporal and physical or spatial constraints on the male's ability to direct sperm towards the ova ${ }^{[1-2]}$. The role of the female sperm storage organs evolution can be understood in terms of the morphometric constraints they place on sperm positioning in Arthropods ${ }^{[3-4]}$. Female millipedes can store the spermatozoa transferred during copulation for long periods in specialized spermathecae ${ }^{[5-7]}$. Viable sperm have been found in the spermathecae of female spirostreptidan millipedes that were only last mated in the previous season ${ }^{[8]}$. Female physiological control may be the ultimate determinant of last male sperm precedence ${ }^{[9-10]}$.

Female morphology in Centrobolus spp. is described with the aim to (1) identify the actual site of sperm storage and discern the stage in the evolution of the sperm storage organ where separation of the spermathecae from the oviduct and the further separation of the sperm insemination duct from the oviduct are recognised as two stages in the evolution of sperm storage organs ${ }^{[11]}$; (2) count the number of spermathecae where single and multiple spermathecae both allow female control over different male ejaculate in different ways ${ }^{[4]}$; (3) remark on how the structure of the spermatheca may affect sperm priority patterns and last male sperm precedence where predicting sperm precedence from the shape of the spermathecae is complicated ${ }^{[12]}$; (4) examine the arrangement of muscle tissue and consider female abilities to control the movement and use of sperm where female morphology can be used as evidence for cryptic female choice ${ }^{[10]}$; $(5)$ test if the female is in a race to surrender or accede selectively where selective acceptance structures include pits and grooves rather than active rejection structures such as erectable spines ${ }^{[13]}$.

Observational evidence for the 'egg simulation' hypothesis in millipedes, which maintains that the eggs have to pass through the temporary sperm store to get released from the vulvae is given $^{[14]}$.

\section{Materials and Methods}

The females of four spiroboloid millipedes: Centrobolus inscriptus (Attems 1928), C. annulatus (Attems 1934), C. fulgidus (Lawrence 1967) and C. ruber (Attems 1928), were sacrificed in ethyl acetate jars within $24 \mathrm{~h}$ of mating with conspecific male(s). The anterior regions of their reproductive tracts were removed by cutting away the integument between the second and third diplo-segments and pinching the junction between the oviduct and the bursa copulatrix. Dissections were immediately placed onto glass slides and viewed with a Wild M400 light microscope. Additional specimens were stored in $70 \%$ ethanol (EtOH) before histological sectioning. On removal from EtOH, a single specimen of each species was selected based on the quality of the dissection. The bursa copulatrix was embedded in paraffin wax (melting point $56-60{ }^{\circ} \mathrm{C}$ ). Sections (1-3 $\mu$ m thick) were cut on a rocking microtome, stained in haematoxylin/eosin and mounted on glass slides in DPX (Gurr) ${ }^{[15]}$. 
Additional vulvae were removed from EtOH, dehydrated and prepared for Scanning Electron Microscopy (SEM). SEM micrographs were produced on Cambridge S200 and Leica 440 scanning electron microscopes.

\section{Results}

No interspecific differences in the external structures of the vulva and bursa copulatrix were seen under the light microscope. No differences between oviducts and associated tissues from stained slides were seen. Thus the female reproductive morphology is only described for $C$. inscriptus.

The opaque nature of the female reproductive tract allowed the form of the major components to be distinguished through the vulva membranes. The vulvae were simple invaginations of the body wall that opened behind the second pair of legs. Within each vulva was a single bursa copulatrix (henceforth bursa). The bursa was a laterally compressed structure with a chitinous hinge that articulates two plates. Access to the bursa could only be gained by severing the connecting tissue and pulling the plates apart. The surface of these plates was scalelike in appearance with the occasional seta and pit. The most distinctive features were the short row of approximately ten hairs pointing inwards. The anterior opening of the bursa was covered by an operculum, which when displaced, revealed the opening of the oviduct. A comparison of sections from the upper and lower regions of the bursa revealed that the sperm insemination duct was separate from the oviduct. The insemination duct or furrow tapers further down to a narrow duct, which lead into single spermatheca ampullae. The duct leading from the insemination furrow of the bursa was narrow. The sperm storage organ occupies less than $10 \%$ of the bursa volume; an estimate based on the success of serial thin sectioning in bisecting it. The sperm formed a compact motionless mass in the distal portion of the long tubular spermatheca. The spermatheca was surrounded by bursa gland cells.

Three sets of muscles were identified ${ }^{[16]}$ : (1) The muscles of the bursa fan outwards from the tissue surrounding the oviduct and connect with the bursa plates, (2) gutter apodematique fan out in opposite directions connecting the spermatheca to each bursa plate, (3) heavily sclerotized region in the lower insemination duct is the confluence site for the sensorium. The presence of a fully developed egg in the bursa immediately after mating was observed in C. inscriptus $(\mathrm{n}=1)$.

\section{Discussion}

The general form of the female reproductive tract was conserved at the genus level. The distendable properties of the vulva membranes allow the male genitalia to penetrate and contact the insemination site during copulation. The sperm storage organ is at stage II of sperm storage organ evolution as insemination duct, spermatheca and oviduct are separate ${ }^{[10]}$. This is like all juliform millipedes with indirect sperm transfer by the gonopods (progoneate mating).

The insemination duct provides a temporary sperm storage site when ejaculate inseminated exceeds the capacity of the spermatheca. Ejaculate volume and the time that it spends in the temporary store determine its fate ${ }^{[1,9,17]}$. Larger ejaculate volumes fill both temporary and spermathecal sperm stores. The length of time that the sperm are stored depend on: (1) where it is initially positioned, (2) sperm competition, and (3) female control.

C. inscriptus plates of the bursa articulate proximally and function as a prehensor to receive sperm by mechanical gate opening [11]. Once sperm are received they immediately occupy the temporary store. The sperm are saucer-shaped, aflagellate and do not pass through metamorphosis (described for $C$. ruber ${ }^{[18]}$ ). Sperm movement must be affected by female processes ${ }^{[10]}$. The sensory apparatus or facilities considered as a whole regulate the passage of sperm from the temporary store into the spermatheca. Sensory muscles connect the spermatheca to the wall of the bursa and control ejaculate entrance/exit via the furrow ${ }^{[19]}$.

The eggs develop in paired ovaries within a common median ovitube that runs from about the 15th diplosegment to the last podous ring ${ }^{[6]}$. The mature eggs travel in single file along the common median ovitube which bifurcates anteriorly into two short oviducts. The eggs have to pass through the temporary sperm store to get released from the vulvae. Evidence for the 'egg simulation' hypothesis verifies insemination and oviposition are coupled ${ }^{[14]}$. Male gonopods stimulate the passage of ova causing (1) mechanical tensions on the basis of the vulva and the connection between the bursa and the operculum, and (2) removal of sperm from around the opening of the spermatheca in the insemination duct. The presence of a fully developed egg in the bursa immediately after mating supports egg simulation. Peristaltic contractions of the oviduct presumably serve to regulate egg release depending upon optimum fertility periods ${ }^{[20]}$.

The stage II sperm storage with a single spermatheca constrains last male sperm priorities. Males have full access to the temporary sperm stores, provided that the bursa is kept open and that the sperm remain there during re-mating. The opportunity for direct sperm removal from the spermatheca is denied since the inlet duct is narrower than the distal lamella of the male gonopod. In many diplopods, the lumina of the receptacula or spermatheca is too narrow for male gonopods to access [6, 16, 21]. Sperm displaced from the temporary sperm may affect displacement from the spermatheca by a flushing strategy of flooding the oviduct with sperm ${ }^{[10]}$.

In conclusion, (1) the actual site of sperm storage is inaccessible to direct sperm removal, (2) a single sperm store indicates female control by variation in the timing of insemination and re-mating interval [1, 17], (3) the bursa is distendable and its shape has little bearing on sperm precedence. Muscles with sensory innovations are proposed to control the spermathecae causing sperm to be drawn in when they contract and expelled when they relax.

\section{Acknowledgements}

This research was made possible through facilities at UCT Medical School, a UCT Research Scholarship, FRD bursary and FNB loan.

\section{References}

1. Cooper MI. Competition affected by re-mating interval in a myriapod. Journal of Entomological and Zoological Studies. 2015; 3:77-78.

2. Cooper MI. Elaborate gonopods in the myriapod genus Chersastus (Diplopoda: Trigoniulidae). Journal of Entomological and Zoological Studies. 2015; 3:235-238. 
3. Alexander RD, Marshall DC, Cooley JR. Evolutionary perspectives on insect mating. In: Choe JC, Crespi BJ (eds) The Evolution of Mating Systems in Insects and Arachnids. Cambridge University Press, Cambridge, 1997, 4-31.

4. Hellriegel B, Ward PI. Complex female tract morphology: its possible use in postcopulatory female choice. Journal of Theoretical Biology. 1998; 190:179-186.

5. Snider RM. Growth and survival in Polydesmus inconstans (Diplopoda: Polydesmidae) at constant temperatures. Pedobiologia, 1981; 22:345-353.

6. Hopkin SP, Read H. The Biology of Millipedes. Oxford University Press, Oxford, 1992.

7. Wigglesworth VB. Principles of insect physiology. Metheun, London, 1965.

8. Barnett M. Sex in southern African Spirostreptida millipedes: mechanisms of sperm competition and cryptic female choice. Dissertation, University of Cape Town, South Africa, 1997.

9. Barnett M, Telford SR, Tibbles BJ. Female Mediation of Sperm Competition in the Millipede Alloporus uncinatus (Diplopoda: Spirostreptidae). Behavioural Ecology and Sociobiology 1995; 36:413-419.

10. Eberhard WG. Female Control: Sexual Selection by Cryptic Female Choice. Princeton University Press, Princeton, 1996.

11. Eberhard WG. Sexual selection and animal genitalia. Harvard University Press, Massachusetts; 1985.

12. Ridley $M$. The incidence of sperm displacement in insects: four conjectures, one corroboration. Biological Journal of the Linnean Society. 1989; 38:349-367.

13. Arnqvist G, Rowe L. Sexual conflict and arms race between the sexes: a morphological adaptation for control of mating in a female insect. Proceedings of the Royal Society of London B, 1995; 261: 123-127.

14. Tadler A. Functional morphology of genitalia of four species of julidan millipedes (Diplopoda: Nemasomatidae; Julidae). Zoological Journal of the Linnean Society 1996; 117:1-15.

15. Humanson GL. Animal tissue techniques. W. H. Freeman \& Company, San Francisco, 1962.

16. Brolemann HW, Lichtenstein JL. Les vulves des diplopodes. Archives de zoologie experientale et génerale 1919; 58: 173-218.

17. Barnett M, Telford SR. The timing of insemination and its implications for sperm competition in a millipede with prolonged copulation. Animal Behaviour 1994; 48:482484.

18. Warren E. On the male genital system and spermatozoa of certain millipedes. Annals of the Natal Museum 1934; 7:351-402.

19. Seifert B. Anatomie und Biologie des diplopoden Strongylosoma pallipes Oliv. Zoomorphology, 1932; 25:362-507.

20. Austin CR. Sperm fertility, viability and persistence in the female tract. Journal of Reproduction and Fertility, 1975; 22:75-89.

21. Tadler A. Genitalia Fitting, Mating Behaviour and Possible Hybridization in Millipedes of the Genus Craspedosoma (Diplopoda, Chordeumatida, Craspedosomatidae). Acta Zoologica, 1993; 74:215-225. 